\title{
The Behavior of Variable Zone for Concave Arcs -Fin of Heat Sink with Multi Air Jet Impingement
}

\author{
Dalmn Yaseen Taha \\ Asst. Prof. Dr. Dhamyaa Saad Khudhur \\ Asst. Prof. Dr. Dr. Layla M. Nassir \\ Mechanical Eng, College of Engineering, Mustansirya University , Baghdad, Iraq
}

\begin{abstract}
Novel array arcs- fin heat sink $7 \times 2$ with $6 \times 2$ multi air jet impingement are presented in this paper by using numerical simulation. Temperature distribution of jets diameter of $5 \mathrm{~mm}$ and arcs- fin heat sink with variety shapes at constant radius of $45 \mathrm{~mm}$ are evaluated. Reynolds number ranges from $7000-11000$. The study has been done at constant $\mathrm{Z} / \mathrm{d}=6$ and constant heat flux $=8333.33 \mathrm{~W} / \mathrm{m}^{2}$. The best shapes of fins has an effective role in improving the rate of heat transfer .In this paper, the design concerned in arcs ships to construct fin geometry. Four concave arcs constricted the shape of fins heat sink for model A. This model has been changed to construct models (B-C-D-E) by reflect two concave arc from it to be convex arc. All five models at the same radius. The five configurations were comparative between each other and the best model comparative with flat plate heat sink. It is observed that model $\mathrm{D}$ of heat sink showed best temperature dissipation than the others.

The results of this paper can help to select heat sink that meets a design's thermal, Power, packaging and cost requirements (specialized in arcs fins) with array of impingement jet, which is a popular used in cooling electronic devices.
\end{abstract}

Keywords: arcs -fin heat sink; array of impingement jet; CFD.

DOI: $10.7176 / \mathrm{CMR} / 13-2-02$

Publication date:May $31^{\text {st }} 2021$

\section{Introduction}

High performance of heat dissipation from electronic device is important appropriate to maintain a systems performance and reliability, also to conserve a compact size and to lower the operating cost. One of the best components used in such cooling systems is the heat sink. The idea of heat sink cooling is to provide extend surface area for dissipating the heat load from the device [1]. Aluminum is one of the best material industrial the heat sinks due to light weight, easily in industrial, lower cost with acceptable performance [2].

The types of heat sink are variety, with different geometries of the fins, and working with: natural or forced convection. This paper focuses and describe on the thermal performance of an arcs- fin array heat sink with the air flow enters the fin-bundle perpendicular to the base of the fin. Thin boundary layer is formed on a heated target surface in jet impingement technique, which results in higher convective heat transfer coefficient. A lot of studies utilized air fluid on multi jet impingement on flat plate or extended surfaces, but at the traditional shape like (pin- fin), (rectangular- fin) and (hexagonal shape) with array of jet or single .It has been reported that novel of array impingement jets have a distinguishing of multiple stagnation regions which results in the improvement of heat transfer.

The studied of steady state with forced convection for the enhancement of heat transfer achieved by indirect techniques (the passive techniques) here some of researcher studied:-

TM Jeng et al [3] investigated the effects of the relative length of the heat sink, the distance between the nozzle and the fin tip, jet Re, and the rotational Re on fluid flow were studied, as well as the heat transfer behaviors of an air jet impingement on a rotating pin-fin heat sink under smoke visualization. N. K. Chougule et al. [4] studied the array of $4 \times 4$ pin-fin heat sink with single and $3 \times 3$ array air jets. The results explained that multi-jet impingement showed 3-4 times greater cooling by single jet. Also the variety of the range in temperature distribution was lesser in multi jet impingement. N. K. Chougule et. al. [5] enhanced numerically the heat transfer in electronic devices. The effect of using multi air jet impingement on aluminum pin fin heat sinks with effusion slots on the nozzle plate for different $\mathrm{H} / \mathrm{d}$ ratio were studied. Reynolds number range from (11000 to 49000) at constant heat supply (30) W. The results showed that the at smaller H/d ratio heat transfer was more effective and the higher Reynolds number yields more heat transfer coefficient. Xueguan Song et. al. [6] presented the optimization and design of a plate-fin type heat sink which cooled by impingement jet. By using the CFD, the flow and thermal fields were simulated. Also the thermal resistance was estimated. A. J. More et. al. [7] investigated experimentally the thermal performance of pin fin heat sink under unconfined and semi confined conditions. Multi-jet impingement technique was studied with varied Reynolds number from (6000 to 12000). The result showed that the distance from jet plate to the target heated surface $=6$ was good agreement for both unconfined and partially confined cross flow arrangement. Experimental results revealed that better heat transfer enhancement occurs for partially confined cross flow compared to unconfined cross flow 
arrangement was 4 to 5\% more. Rıdvan Yakut, et. al. [8] determined the experimental and numerical analytic by ANSYS - Fluent CFD program. Impingement air jet was used with hexagonal- fins heat sink. Experiments were performed for jet diameter $(\mathrm{d})=50 \mathrm{~mm}$ at constant heat flux. The results showed that the maximum Nusselt values and Pressure coefficients were found for $\mathrm{Y} / \mathrm{d}=1$ and fin height $=100 \mathrm{~mm}$. Sk. Esub Basha et. al. [9] determined the most effective heat transfer parameters by using taguchi's optimization method where the orthogonal array $\mathrm{L}_{16}\left(4^{2} 2^{9}\right)$ for the cooling applications. CFD model performed after optimizing technique by considering results of taguchi method. Experiments were performed for nozzle diameter $=(20) \mathrm{mm}$, at $\mathrm{z} / \mathrm{d}=(4,6$, 8 and 10). The two different velocity values $=(8,9) \mathrm{m} / \mathrm{sec}$ were used. The result showed that the highest Nusselt number were obtained for $\mathrm{Z} / \mathrm{d}=6$ and $\mathrm{U}=8 \mathrm{~m} / \mathrm{sec}$. Furthermore the highest heat flux and heat transfer rate were obtained at $\mathrm{Z} / \mathrm{d}=6$ for both numerical and experimental results. Zhipeng Duan et. al. [10] investigated the pressure drop $(\Delta \mathrm{p})$ of the plate - fin heat sink subjected to rectangular impinging of air flow. Widths, fin heights, and the shapes of flow were run in the numerical simulations in different inlet. Reynolds number was in laminar flow. The numerical results showed that, at the same flow rate, $(\Delta \mathrm{p})$ reductions with the rise of the impingement inlet width and growths significantly with the increase of the fin height. Besides $(\Delta \mathrm{p})$ for an impinging plate- fin heat sink without elliptic bottom profiles was larger than that with elliptic bottom profiles.

However from vast literature survey it is observed that array of air impingement jet at new distribution jets on 5 models of (concave, concave - convex) arcs- fin heat sink (AFHS) is still interesting. The current study depends on $(7 \times 2)$ array at variety distributed of (concave - convex) arcs for fin heat sink with $(60 \times 60)$ base are chosen to enhance the dissipation of heat from a heat target surface by multi air jets $(6 \times 2)$ of (5) $\mathrm{mm}$ dia. The arrangement of the nozzle as shown in (Fig 1) and the arrangement of fins with its five models are shown in (Fig 2).

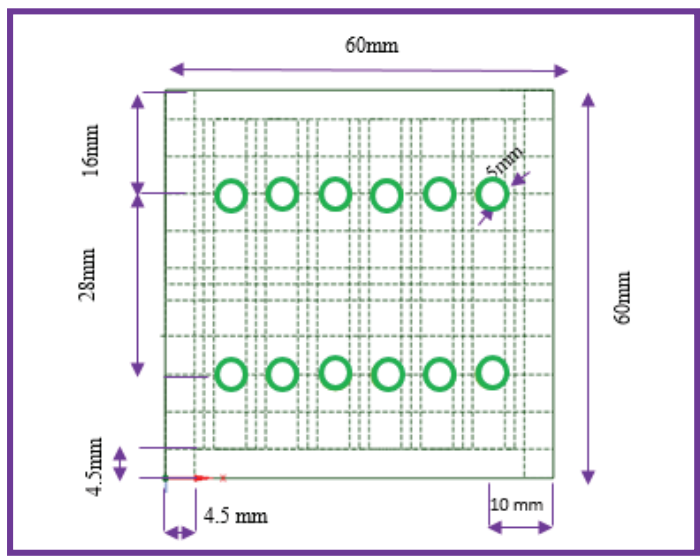

Fig 1.The arrangement of the nozzle

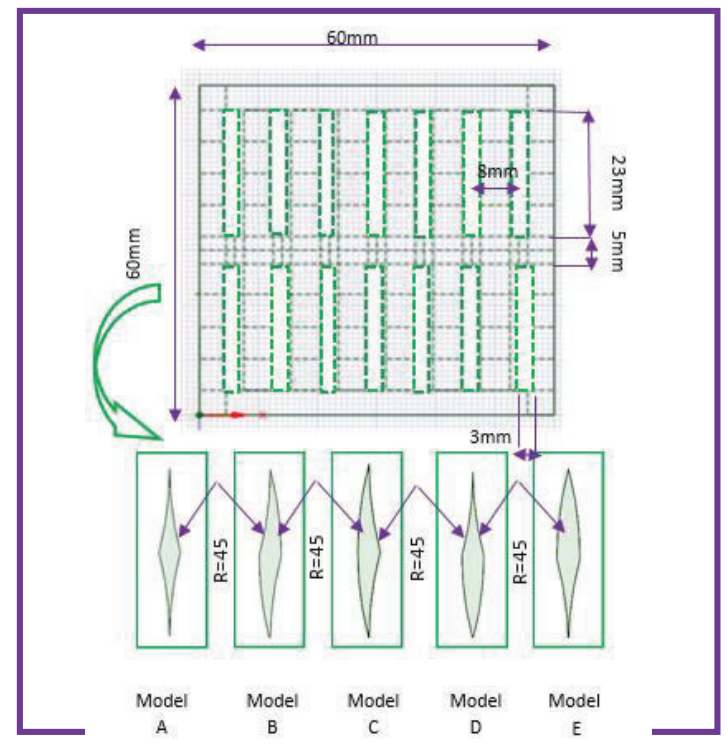

Fig 2.The arrangement of the fins with its shapes

The objective of this study is to determine the rate local temperature with fins to local temperature without fins for five models in order to understand the fins characteristics. The influence of Reynolds number and the velocity distribution are examined in detail. 


\section{Governing equation}

Conservation of mass equation [2]

Conservation of linear momentum equation [2]

- x- Component

- y - Component

........... (3)

-z- Component

(4)

Energy equation [2]

........... (5)

(6)

The fluctuating terms appearing in Eq. (2) to (4) represent the components of the "turbulent momentum flux" and they are usually referred to as additional "apparent stresses" or "Reynolds stresses" resulting from the turbulent fluctuations. The fluctuating terms appearing in Eq. (5) represent the components of "the turbulent energy flux". [2]

\section{Physical problem}

A physical model of a multi-jet impinging on (AFHS) are analyzed, show (Fig 3). The jet is discharged with length (l) and diameter (d) is directed towards the (AFHS) with base $(60 \mathrm{~mm} \times 60 \mathrm{~mm} \times 6 \mathrm{~mm})$ vertically. Constant value of heat flux was subjected from bottom. All other walls are adiabatic except top surface. After impingement, the flow (air) exit from four side from opening with (minimum cross flow).

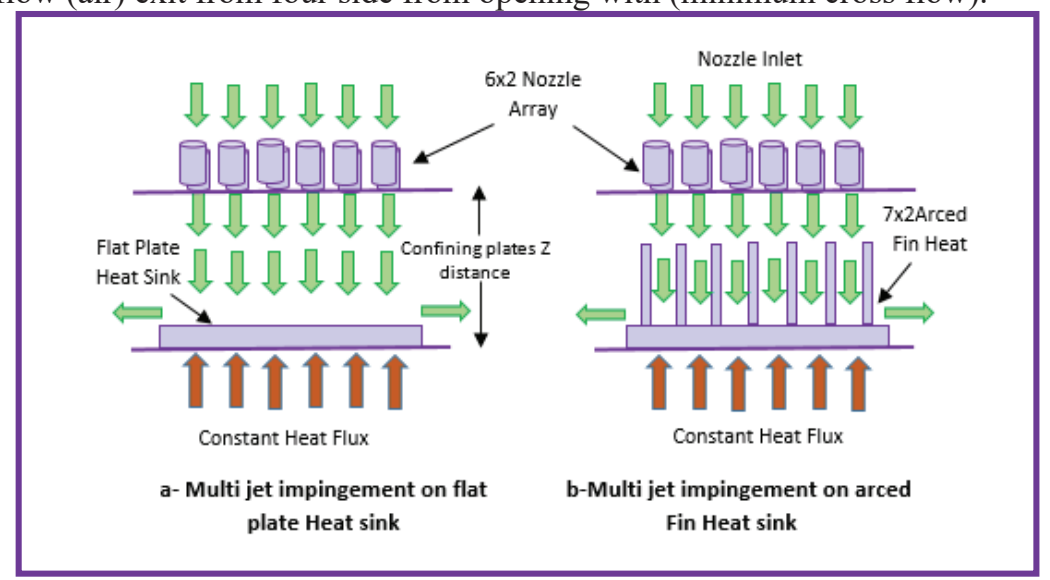

Fig 3. Physical model of $6 \times 2$ multi jet with $7 \times 2$ arcs- fin heat sink

Fin array consist of high $(\mathrm{H})$, radius $(\mathrm{R})$ and transverse pitch of arc fin array is $\mathrm{S}_{\mathrm{T}}$, longitudinal pitch of arc fin array is $S_{L}$, the thickness of the fin is t. nozzle plate consist of $(n-1 \times n)$ array with (d)diameter. Heat sink material is aluminum.

\section{Mesh - boundary conditions}

Meshing of all models of (AFHS) and computation domain are shown in (Fig 4). The domain of interest is rectangular geometry, the fin height in (Z- direction). The longest domain in (X-direction) and (Y-direction) for the shortest domain. The computational domain is bounded by: solid domain (AL) and fluid domain (air). Stagnant air is filled the solution domain. The heat is generated inside the heat sink at a uniform rate with constant heat flux from the base.

The four side's faces of domain are applied to Pressure boundary condition. The top face and bottom face of the domain are in adiabatic wall condition. The constant heat flux is applied in the bottom of heat sink at value $8333.33 \mathrm{~W} / \mathrm{m}^{2}$. The four sides of heat sink are adiabatic. The flow is assumed steady with turbulent and incompressible and flow in three dimensional. The assembly meshing at nodes (726316) with elements (3814457). 


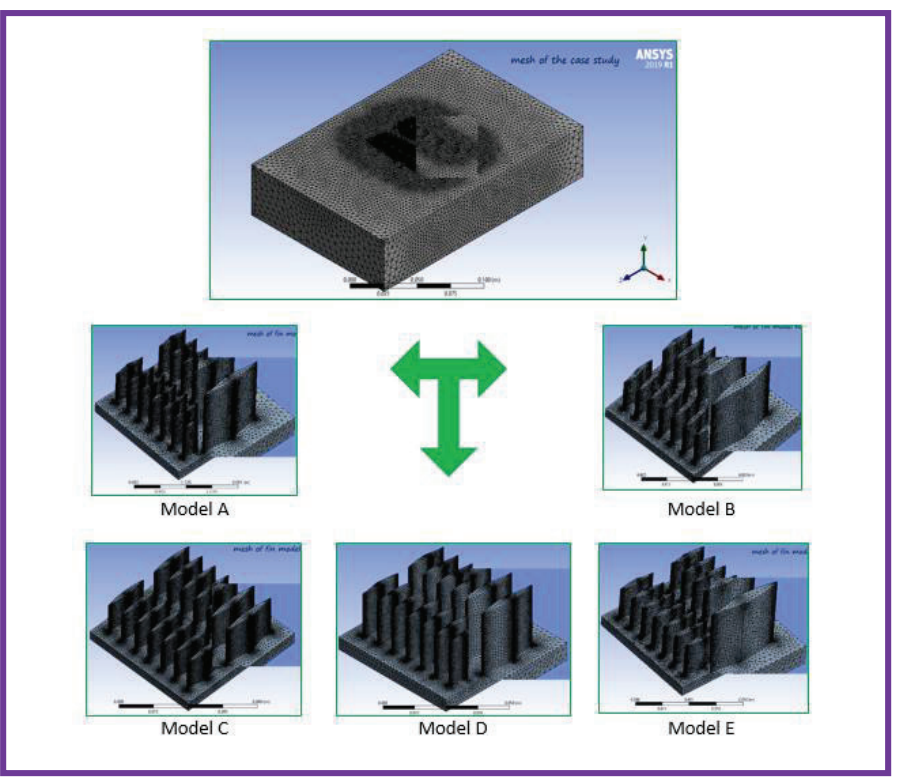

Fig 4.Meshing of arcs- fin heat sink and computation domain

Table 1: Description modeled of the multi air jet impingement

\begin{tabular}{|l|l|}
\hline$(\mathrm{n}-1 \times \mathrm{n})$ & $6 \times 2$ \\
\hline No. of jets & 12 \\
\hline Diameter of nozzle & $5 \mathrm{~mm}$ \\
\hline longitudinal pitch of jet array & $8 \mathrm{~mm}$ \\
\hline transverse pitch of jet array & $28 \mathrm{~mm}$ \\
\hline Jet to target plate spacing & $30 \mathrm{~mm}$ \\
\hline Ratio of jet to target plate spacing and nozzle & 6 \\
\hline Jet Reynolds based on jet velocity & $7000,9000,11000$ \\
\hline
\end{tabular}

Table 2. Description modeled of the heat sinks

\begin{tabular}{|c|c|c|c|}
\hline Length $(\mathrm{L})$ & $60 \mathrm{~mm}$ & Height of base $\left(\mathrm{t}_{\mathrm{b}}\right)$ & $6 \mathrm{~mm}$ \\
\hline Width $(\mathrm{W})$ & $60 \mathrm{~mm}$ & Space between two row & $5 \mathrm{~mm}$ \\
\hline Height of fin $(\mathrm{H})$ & $20 \mathrm{~mm}$ & Space for edges & $4.5 \mathrm{~mm}$ \\
\hline Fin Thickness $(\mathrm{t})$ & $3 \mathrm{~mm}$ & No. of fins & 14 \\
\hline$\left(\mathrm{S}_{\mathrm{T}}\right)$ & $28 \mathrm{~mm}$ & R & $45 \mathrm{~mm}$ \\
\hline$\left(\mathrm{S}_{\mathrm{L}}\right)$ & $8 \mathrm{~mm}$ & Length of fin & $23 \mathrm{~mm}$ \\
\hline
\end{tabular}

Table 3. Comparison of the arcs- fins heat sink geometry specifications

\begin{tabular}{|c|c|c|}
\hline Models & $\begin{array}{c}\text { No. of } \\
\text { concave arc }\end{array}$ & Shapes configuration \\
\hline A & 4 concave arc & Symmetric concave arcs \\
\hline B & 2 concave arc & Symmetric concave - convex arcs \\
\hline C & 2 concave arc & series concave arcs in Z direction of fin \\
\hline D & 2 concave arc & $\begin{array}{c}\text { series concave arcs in x direction of fin } \\
\text { (divergent from the middle of heat sink) }\end{array}$ \\
\hline E & 2 concave arc & $\begin{array}{c}\text { series concave arcs in x direction of fin } \\
\text { (convergent from the middle of heat sink) }\end{array}$ \\
\hline
\end{tabular}

\section{Result and discussion}

\subsection{Temperature distribution for impingement-heat sink}

The comparative of temperature distribution for jet impingement with heat sink in $\mathrm{Y}-\mathrm{Z}$ plane at fin region and between it, has founded it similarity. Also the temperature distribution in Y-X plane is similar with temperature distribution at Y-Z plane. The plot of comparative between three states is shown in (Fig 5.) give us improvement for the uniform state of our study and the advantage of the multi jet impingement. 


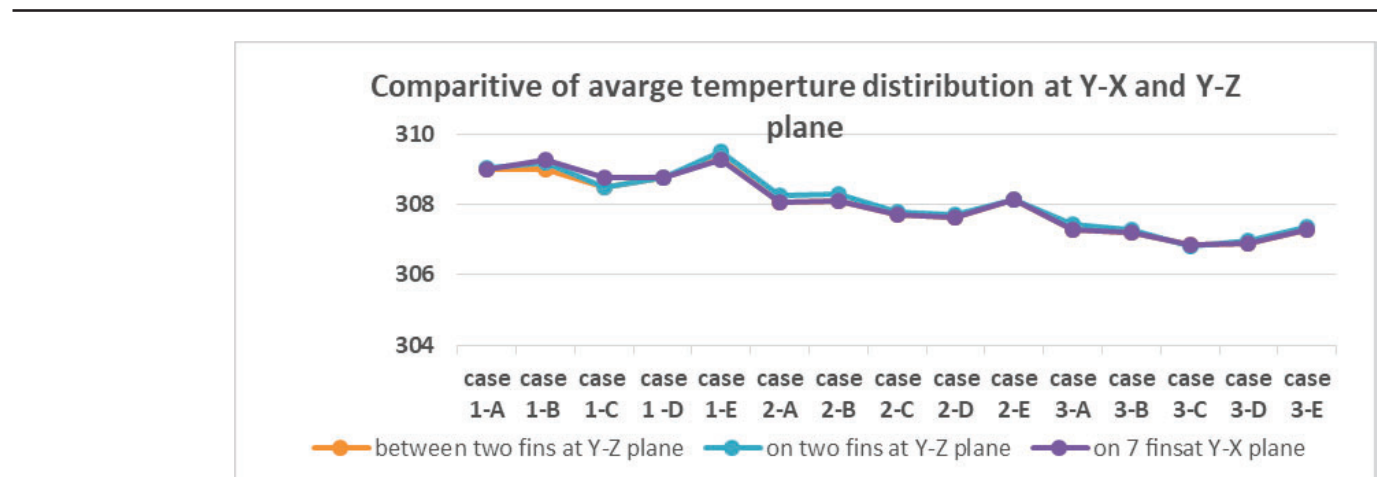

Fig. 5. Comparative plot of average temperature for all domain in Y-X and Y-Z plane at $\operatorname{Re}(\mathbf{7 0 0 0 - 9 0 0 0 - 1 1 0 0 0 )}$

\subsection{Effect of Reynolds number on velocity distribution}

The effects of Reynolds number (Re) on the heat transfer performance of (flat plate) heat sink and (AFHS) under multi-jet $(6 \times 2$ nozzle arrays) impingement are studied at $7000 \leq \mathrm{Re} \leq 11000$ for $\mathrm{z} / \mathrm{d}=6$ by taking cutting in $\mathrm{Y}-\mathrm{X}$ plane (7 fins with 6 jets) as shown in the (Fig 6). The second plane was taking in Y-Z plane.

A. Velocity distribution in Y-X plane

The average velocity vector on 7 fins in Y-X plane is shown in the (Fig 6). All fins in difference cases have thickness in that plane $=3 \mathrm{~mm}$. The momentum has not reduced with constant $\mathrm{Z} / \mathrm{d}$. the potential core zone is predominant.

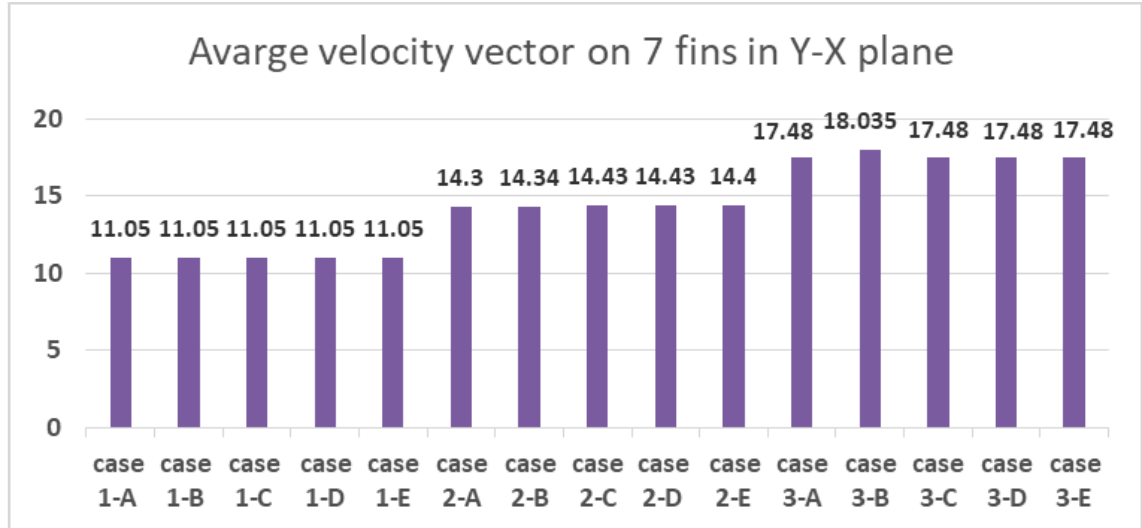

Fig.6 Average velocity vector on7 fins in Y-X plane at $\operatorname{Re}(7000-9000-11000)$

\section{B. Velocity distribution in $\mathrm{Y}-\mathrm{Z}$ plane}

Two planes in Y-Z plane are taken for fin region as shown in (Fig 7) and for the region between fins as shown in (Fig 8). The flow velocity is variables because the effect of fins walls appears in first plane.

It is most important to know the movement of fluid (air) in the space between the fins in array that give as indicate for enhancing the heat transfer [11].

The Comparative plot of average velocity vector for models (A-B-C-D-E), in Y-X plane and Y-Z plane at Re (7000-9000-11000) can show in (Fig 9)

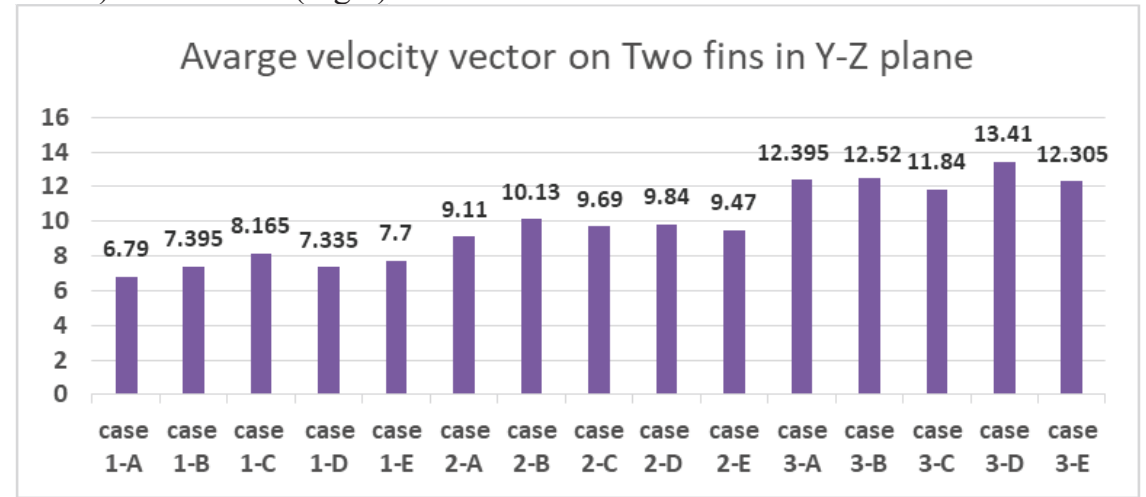

Fig.7 Average velocity vector on fins in $\mathrm{Y}-\mathrm{Z}$ plane for models (A-B-C-D-E) at $\operatorname{Re}(7000-9000-11000)$ 


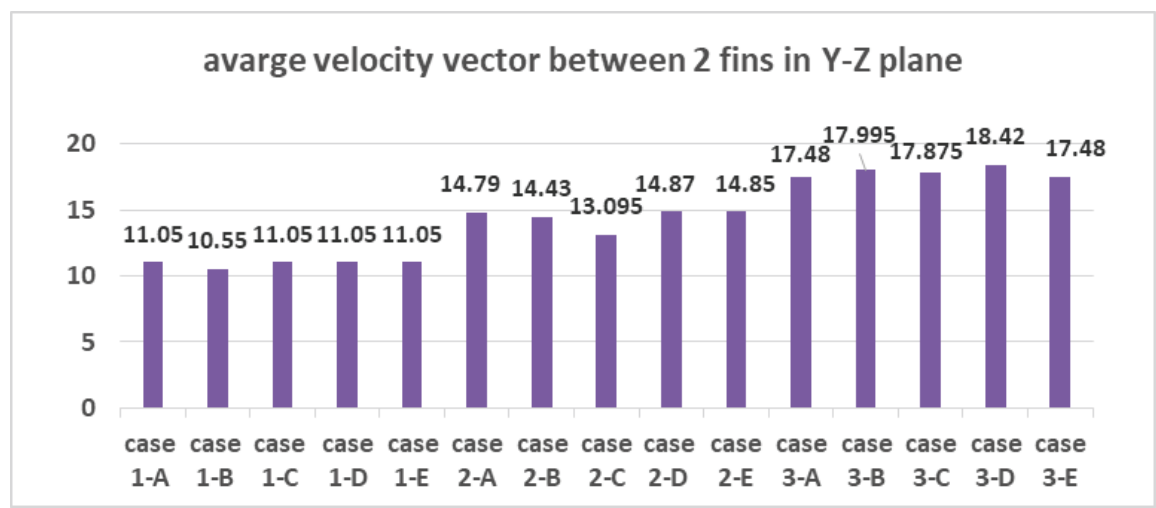

Fig.8 Average velocity vector between fins for models (A-B-C-D-E) at $\operatorname{Re}(\mathbf{7 0 0 0 - 9 0 0 0 - 1 1 0 0 0 )}$

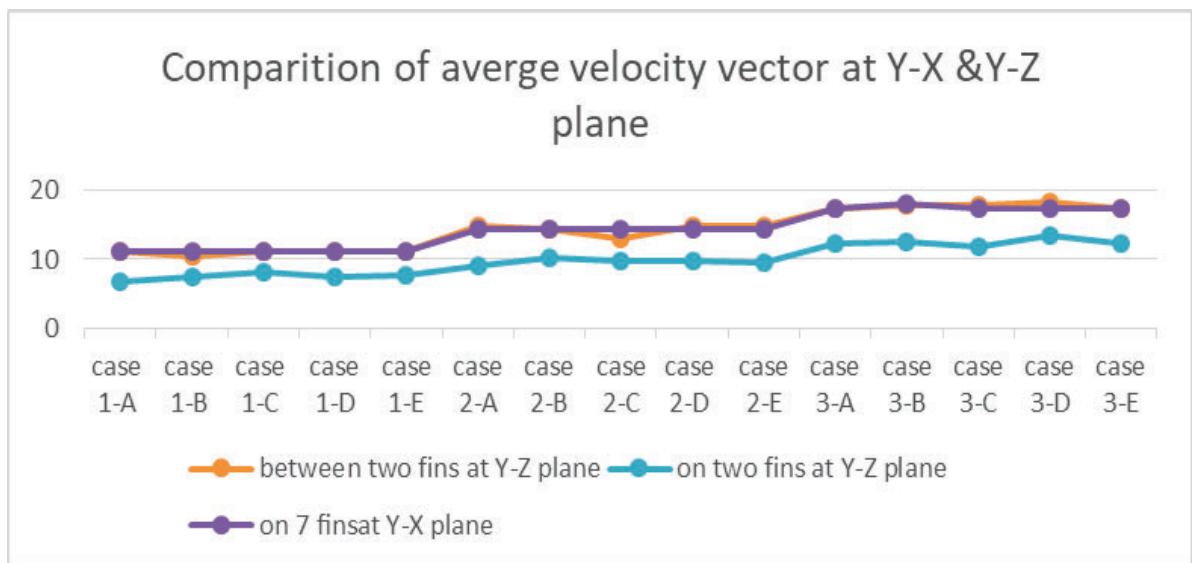

Fig. 9 Comparative plot of average velocity vector for models (A-B-C-D-E), in Y-X plane and Y-Z plane at Re (7000-9000-11000)

5.3 Comparative of temperature distribution with velocity distribution for the domain in $\mathrm{Y}-\mathrm{X}$ and $\mathrm{Y}-\mathrm{Z}$ plane

The importance of studying this section lies in terms of taking the average temperature and the average velocity by making a comparison between them to show the behavior of the domain and give us indication about the relationships between the temperature and velocity. (Figs 10,11 and 12) view the path of average values for each temperature and velocity vector on fins at $\mathrm{Y}-\mathrm{X}$ plane and $\mathrm{Y}-\mathrm{Z}$ plane.

The rate of heat transfer increase with increasing $\mathrm{v}$, while the pressure drop $(\Delta \mathrm{p})$ increasing with velocity too. The pressure drop increases linearly with increasing $\mathrm{Nu}$.

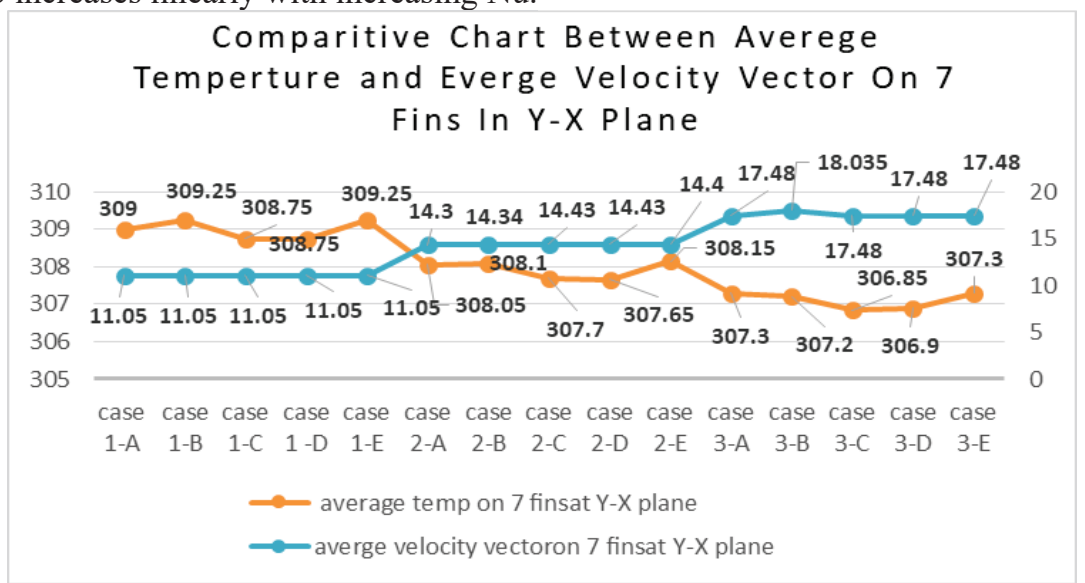

Fig.10. Path of the average values for each temperature and velocity vector on fins at Y-X plane 


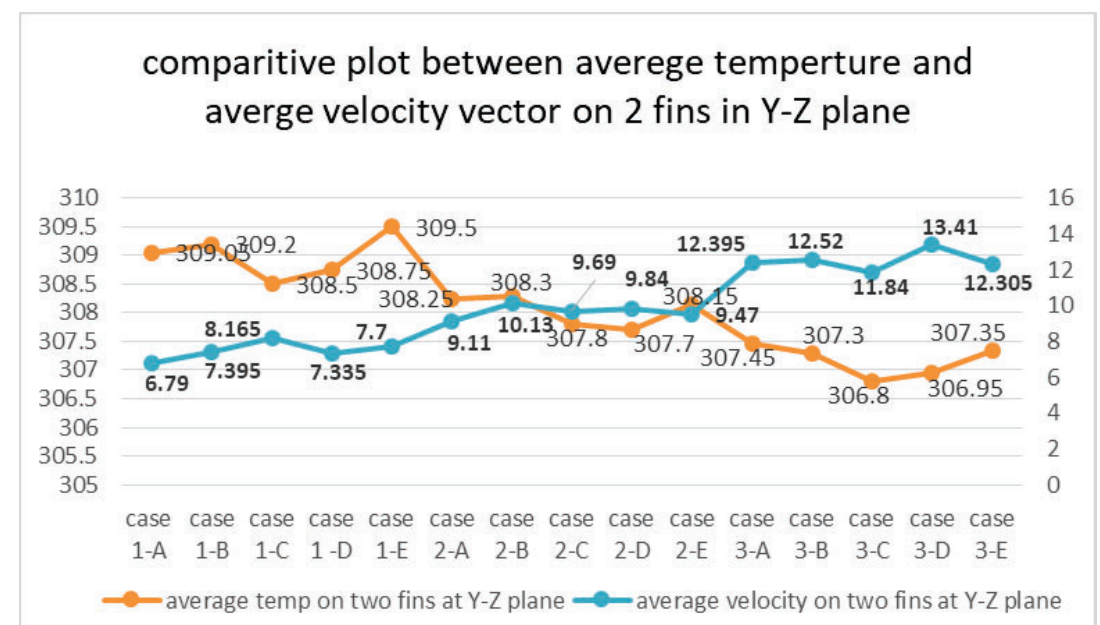

Fig 11. Path of the average values for temperature and velocity vector on fins at Y-Z plane

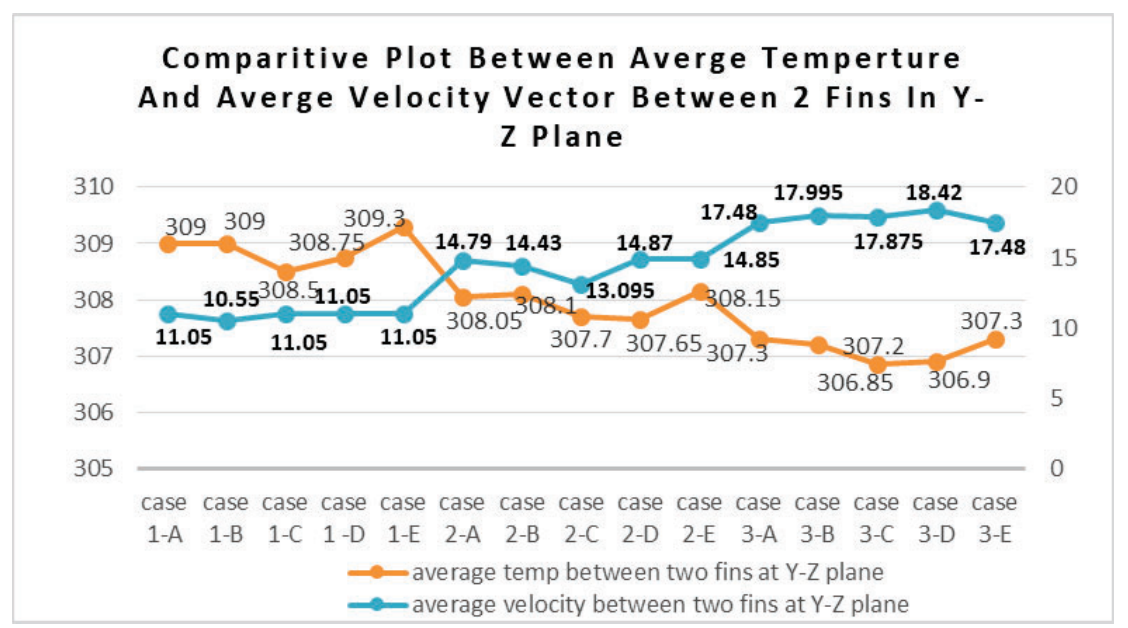

Fig 12. Path of average values for temperature and velocity vector between fins at $Y-Z$ plane

\subsection{Average temperature of the solid}

\section{A. Average temperature of the solid for flat plate heat sink}

The dissipation of heat become more when the Reynolds number increase. The increasing of fluid turbulence over the fin, increase the heat transfer rate [11]. For flat plate heat sink high values of Reynolds number is necessary to avoid damage of electronic device. At $\mathrm{Re}=7000$, the average temperature of the solid for flat plate heat sink is very high $=362.541 \mathrm{k}$. It is unable to spread the heat quickly along its base. The area of the heat sink unable to provide any cooling. While average temperature at $\mathrm{Re}=9000,11000$ are $341.958 \mathrm{~K}$ and $340.094 \mathrm{~K}$ respectively Show the (Fig13). The Comparative plot between average temperatures for (Flat plate) at Re (70009000-11000) can show in (Fig14). 


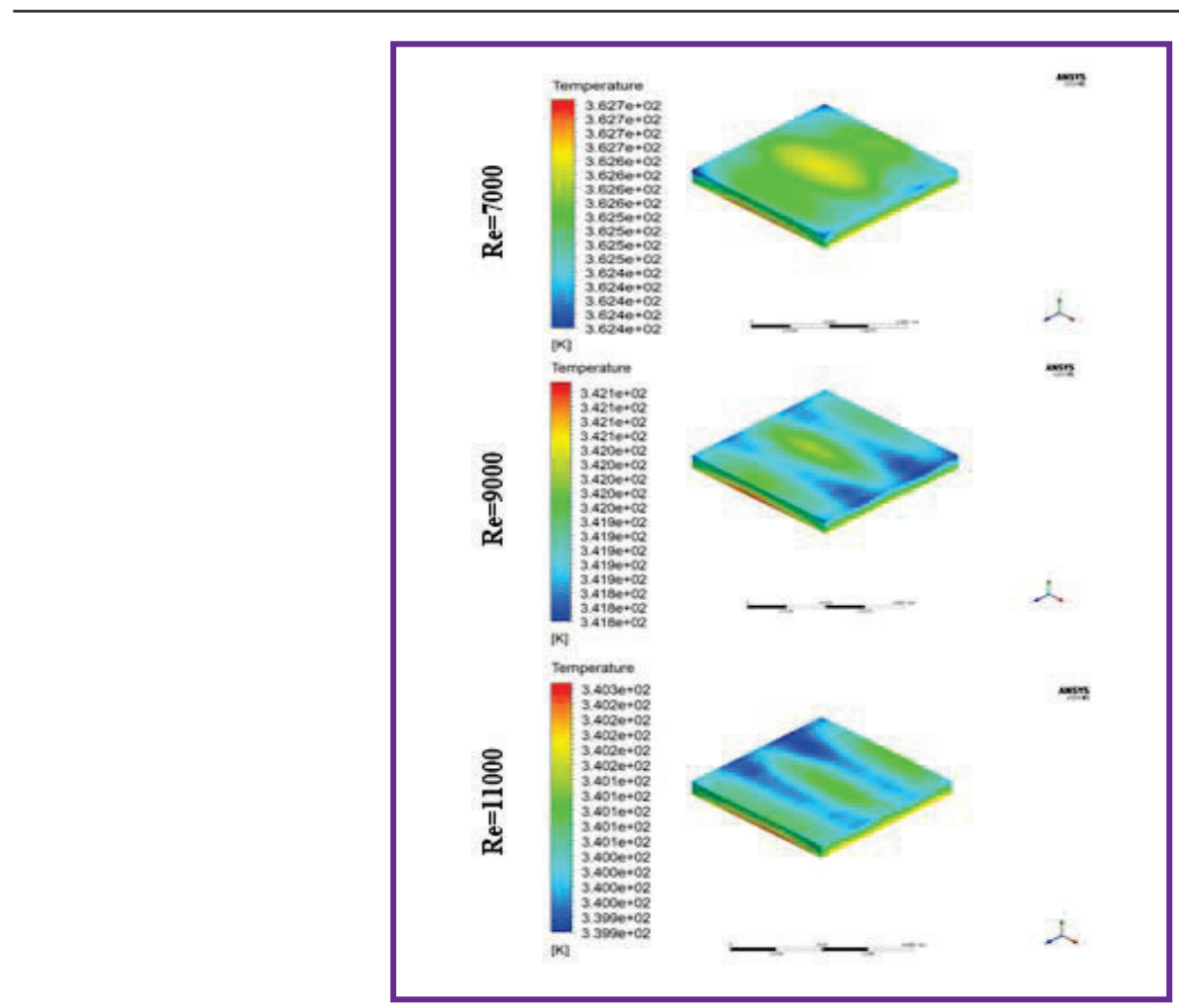

Fig 13. Temperature distribution of the solid for standard (Flat plate) heat sink at $(\operatorname{Re}=7000-9000-11000)$

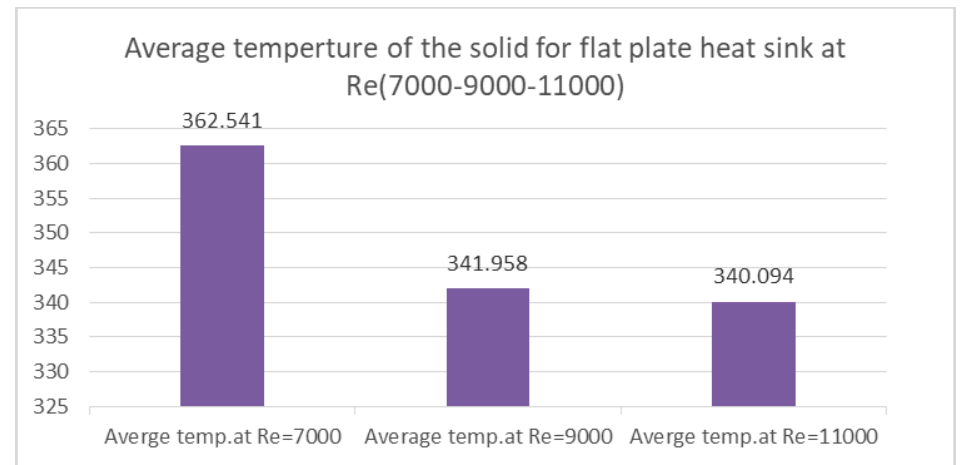

Fig 14. Comparative plot between average temperatures for standard (Flat plate) at $\operatorname{Re}(\mathbf{7 0 0 0}-\mathbf{9 0 0 0 - 1 1 0 0 0 )}$

\section{B. Average temperature of the solid with symmetric fins shape}

At (Fig 15) the (model A) and (model B) are in symmetric shape with in $\mathrm{X}$ and $\mathrm{Z}$ direction. At $\mathrm{Re}=7000$, the average temperature for $($ case $1-A)=316.423 \mathrm{~K}$, while (case $1-B)=317.25 \mathrm{~K}$. Besides, there is a similarity between (case2-A) and (case2-B) at $\mathrm{Re}=9000$. At $\mathrm{Re}=11000$, (case3-A) is better than (case 3-B). The values of average temperature for $($ case $3-A)=312.905 \mathrm{~K}$, while the average temperature for (case $3-\mathrm{B})$ $=313.052 \mathrm{~K}$. The influences of geometric shape with jets impingement gave different indicate to heat transfer at highest Reynolds number. Show the (Figs 15 and 16). 


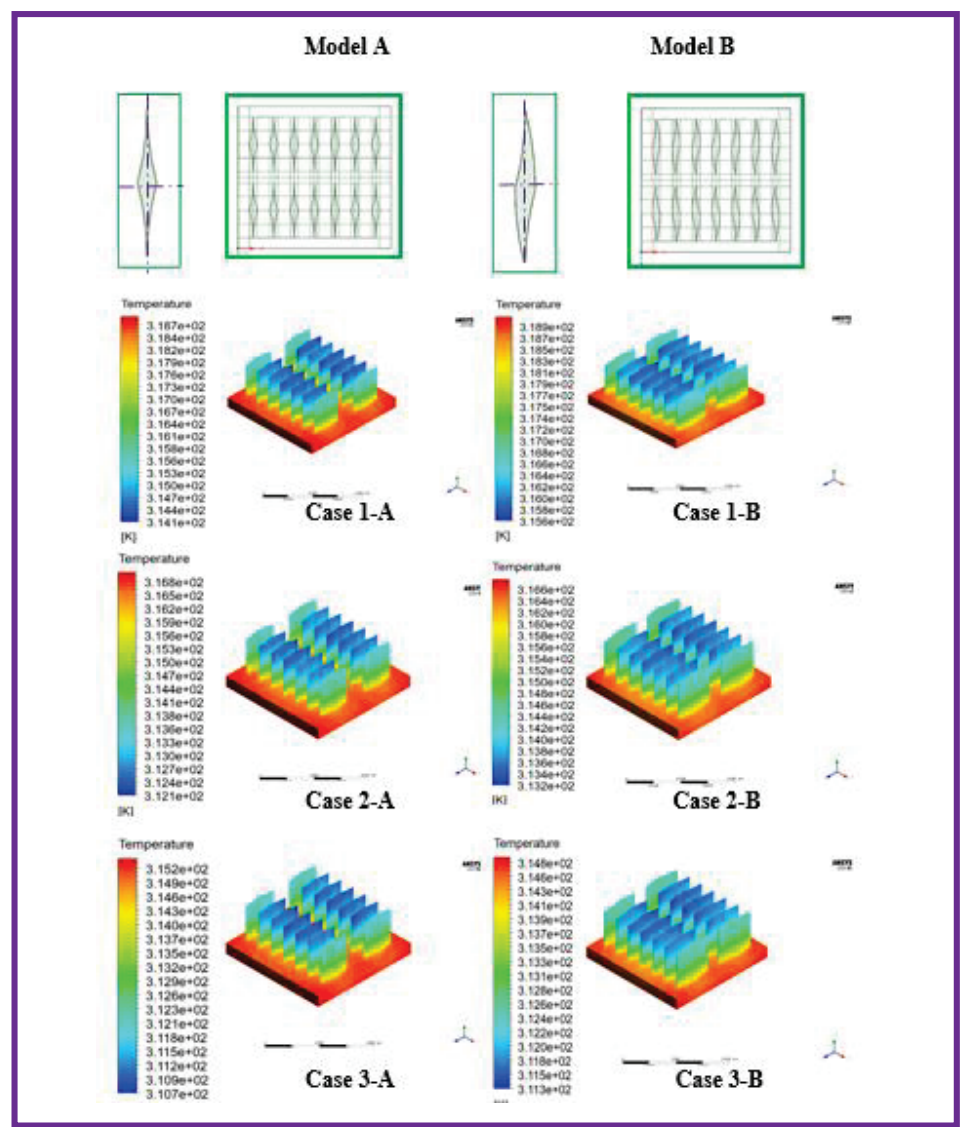

Fig 15. Temperature distribution of the solid for models $(A-B)$ at $(\operatorname{Re}=7000-9000-11000)$.

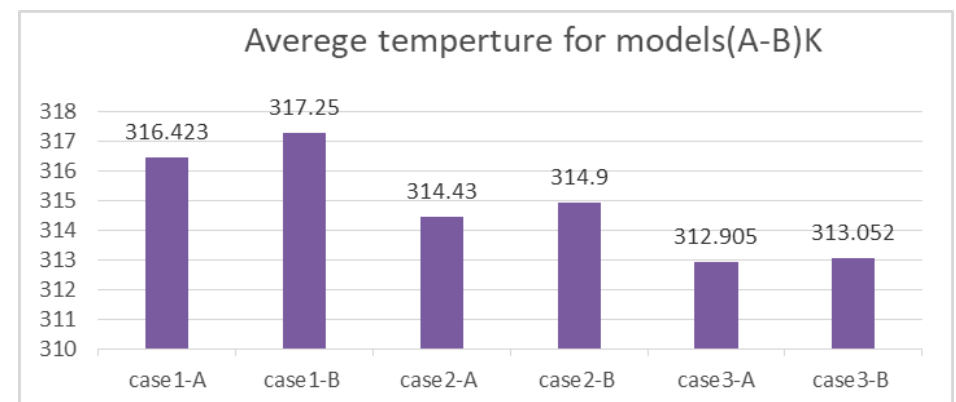

Fig 16. Comparative plot between average temperatures of the solid for models (A-B) at $\operatorname{Re}(7000-9000-11000)$

\section{Average temperature of the solid for symmetric shape in $\mathrm{z}$ direction only.}

(Model D) and (model E) are in symmetric shape within Z- direction show (Fig 17). In spite the shape fins of (model D) are similar to shapes fins of (model E) (only rotated $180^{\circ}$ at same location). But the average temperature for (model D) is better than (model E) in all cases. At $\mathrm{Re}=7000$, the average temperature of (case1$\mathrm{D})=316.15 \mathrm{~K}$, but the value of (case1-E) $=317.229 \mathrm{~K}$. At $\mathrm{Re}=9000$, the average temperature of (case2-D) $=$ $313.91 \mathrm{~K}$, and the value of (case2-E) $=314.91 \mathrm{~K}$. While at $\mathrm{Re}=11000$, the average temperature of (case3-D) and $($ case $3-\mathrm{E})=312.4 \mathrm{~K}$ and $313.15 \mathrm{~K}$ respectively.

The influences of geometric shape with jets impingement gave different indicate to heat transfer. The reflection of its fins gave different result in temperature distribution to dissipate the heat for all values of Reynolds number show (Fig 18). 


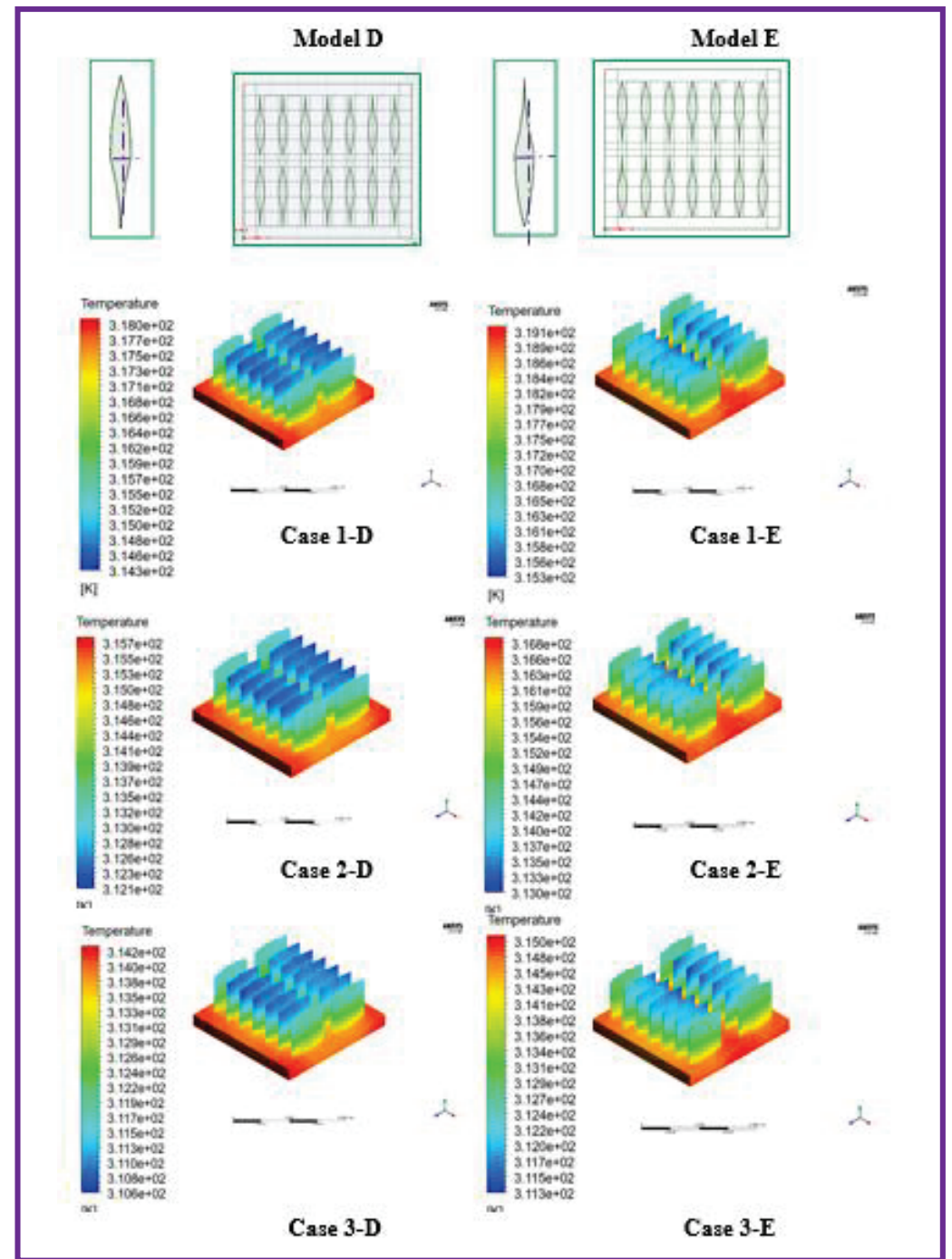

Fig. 17. Temperature distribution of the solid for models (D- E) at $(\operatorname{Re}=\mathbf{7 0 0 0 - 9 0 0 0 - 1 1 0 0 0 )}$.

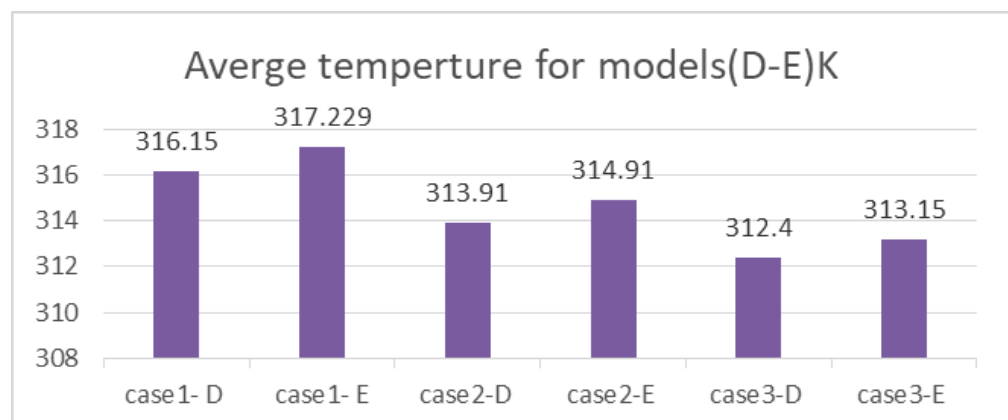

Fig 18. Comparative plot between average temperatures of the solid for models (D - E) at $\operatorname{Re}(7000-9000-11000)$.

D. Average temperature of the solid with concave-convex ended of fins array near the edges of heat sink

(Model B) have (concave-convex) tail in $\mathrm{X}$ and $\mathrm{Z}$ direction at four sides of edges heat sink. (Model C) have (convex-concave) tail in Z- direction only in two sides near the edge of heat sink. While (Model D) have (convex-concave) tail in X- direction only in two sides of fins array near the edge of heat sink. When comparing the results of (models B, C, and D), we founded that at all state of Reynolds number (model B) has the low performance than the other models, besides each of (model C) and (model D) have the same performance. Show (Figs 19) and (Fig 20) 


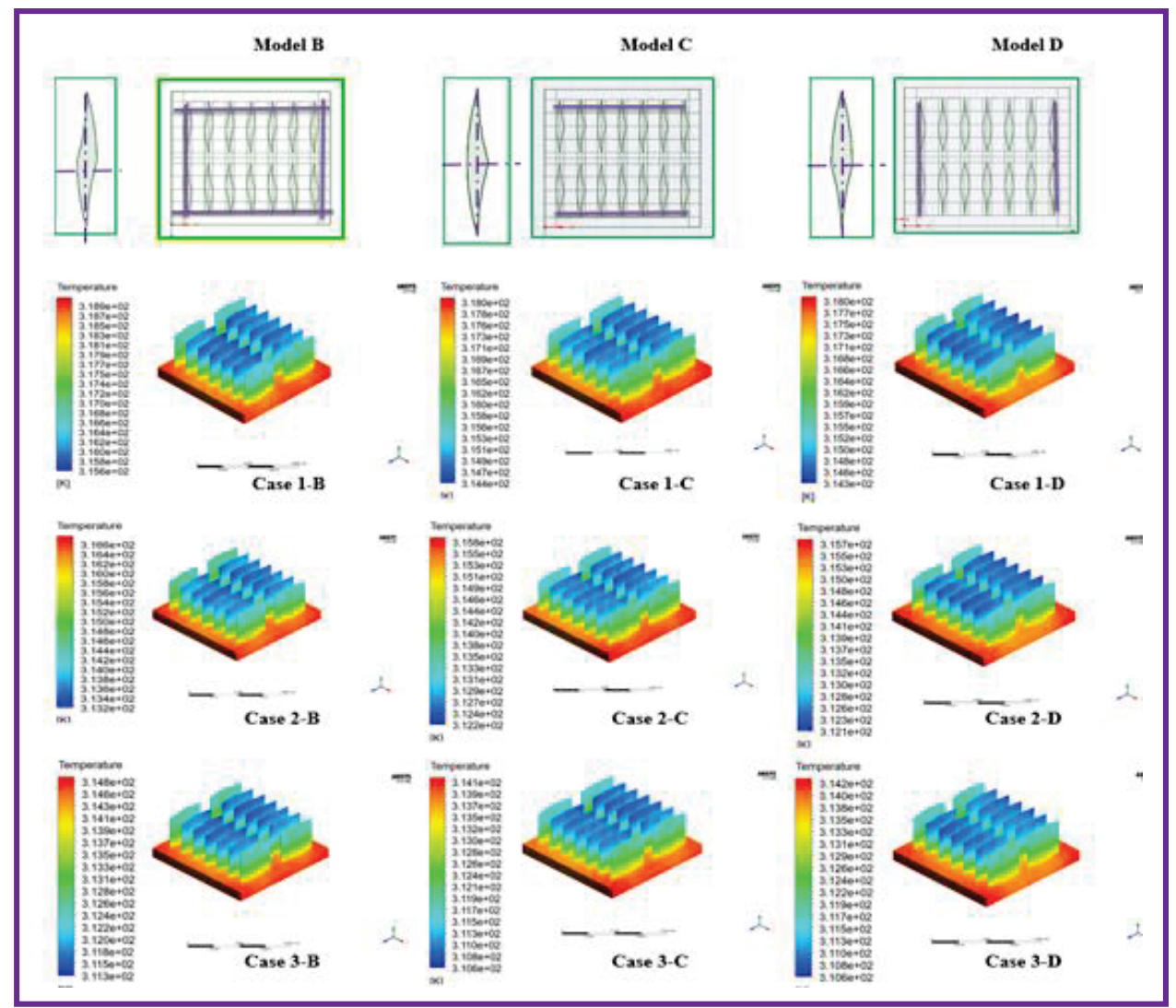

Fig .19 Temperature distribution for models (B- C-D) at $(\mathrm{Re}=7000-9000-11000)$.

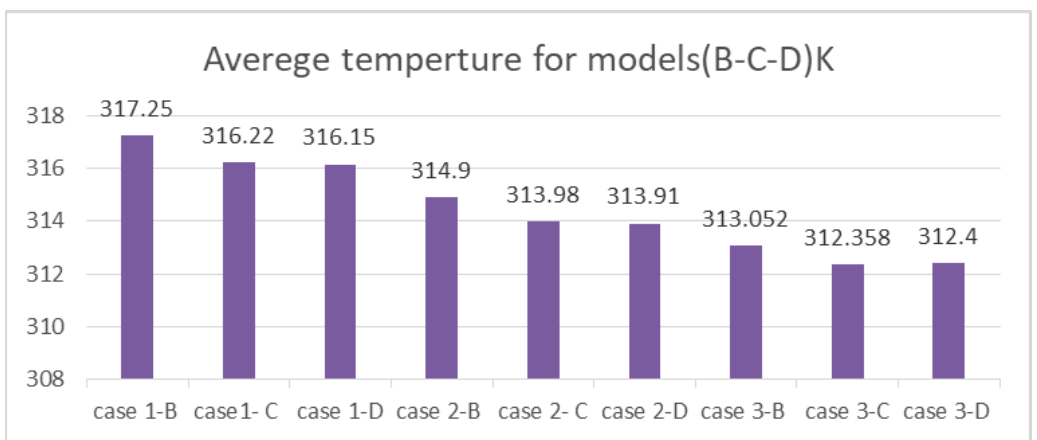

Fig. 20. Comparative plot between average temperatures of the solid for models

(B-C-D) at $\operatorname{Re}(\mathbf{7 0 0 0}$ - 9000-11000).

E. Average temperature of the solid with concave ended of fins array near the edges of heat sink (Model C) have concave end for its fins array at one side of heat sink in X-direction. (Model D) have concave end in its fins array near from the edge of heat sink for two side of heat sink. While (model A), have concave end in its fins array near from the edge of heat sink at four side of heat sink. Concave end for the fins array whether in X or Z direction provided they are close to the edges of heat sink, enhanced the performance. Only at $\mathrm{Re}=9000$, the value of average temperature for (case2-A) have low performance than (case2-C) and (case2-D). Each of (case2-C) and (case2-D) have average temperature $=313.98 \mathrm{~K}$ and $313.91 \mathrm{~K}$ respectively, while (case2-A) have average temperature $=314.43 \mathrm{~K}$. The behavior of the three models at $\mathrm{Re}=7000-11000$ are similarity. Show (Fig 21). 


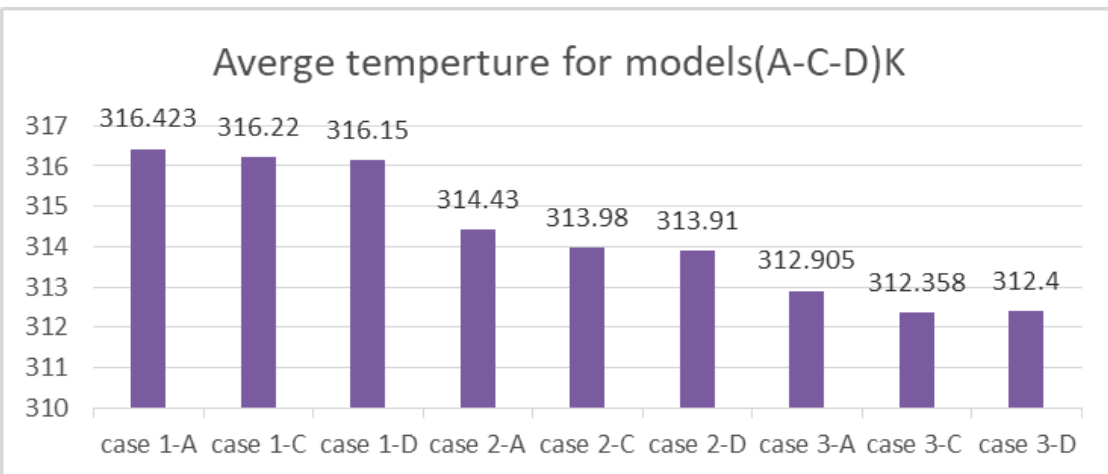

Fig. 21. Comparative plot between average temperatures of the solid for models $(A-C-D)$ at $\operatorname{Re}(7000,9000,11000)$.

F. Average temperature with same number of (concave-convex) arcs.

Each of Models (B, C, D and E) have the same number of concave arc and convex arc. But it gave different temperature distribution with difference average temperature. Show (Fig 22).

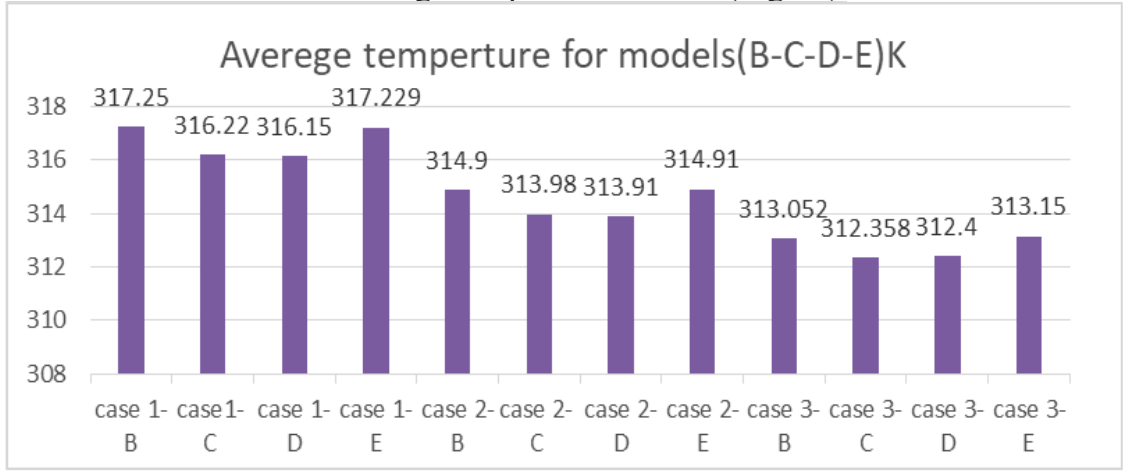

Fig 22. Comparative plot between average temperatures of the solid for models (B -C-D-E) at $\operatorname{Re}(7000-9000-11000)$.

(Table 4) give the summery results of average temperature of the solid for the two types of heat sink (flat plate- fined heat sink). While (Table 5) show the summery of temperature distribution for the solid.

Table 4. Average temperature of the solid for the heat sink (K)

\begin{tabular}{|c|c|c|c|c|c|c|}
\hline \multirow{2}{*}{ Models } & \multicolumn{2}{|c|}{$\begin{array}{c}\text { average Temp.at } \\
\text { Re=7000 }\end{array}$} & \multicolumn{2}{c|}{$\begin{array}{c}\text { average Temp.at } \\
\mathbf{R e}=\mathbf{9 0 0 0}\end{array}$} & \multicolumn{2}{c|}{$\begin{array}{c}\text { average Temp.at } \\
\mathbf{R e}=\mathbf{1 1 0 0 0}\end{array}$} \\
\hline standard & Flat plate & 362.541 & Flat plate & 341.958 & Flat plate & 340.094 \\
\hline model A & case 1-A & 316.423 & case 2-A & 314.43 & case 3-A & 312.905 \\
\hline model B & case 1-B & 317.25 & case 2-B & 314.9 & case 3-B & 313.052 \\
\hline model C & case 1-C & 316.22 & case 2-C & 313.98 & case 3-C & 312.358 \\
\hline model D & case 1-D & 316.15 & case 2-D & 313.91 & case 3-D & 312.4 \\
\hline model E & case 1-E & 317.229 & case 2-E & 314.91 & case 3-E & 313.15 \\
\hline
\end{tabular}


Table 5. Temperature distribution of the solid for the heat sink (K)

\begin{tabular}{|lcc|}
\hline Models & cases & Temperature distribution \\
\hline \multicolumn{2}{|c|}{ Flat plate } & $362.4-362.7$ \\
\hline Model A & 1-A & $314.1-318.7$ \\
\hline Model B & 1-B & $315.6-318.9$ \\
\hline Model C & 1-C & $314.4-318$ \\
\hline Model D & 1-D & $314.3-318$ \\
\hline Model E & 1-E & $315.3-319.1$ \\
\hline \multicolumn{2}{|c|}{ Flat plate } & $341.8-342.1$ \\
\hline Model A & 2-A & $312.1-316.8$ \\
\hline Model B & 2-B & $313.2-316.6$ \\
\hline Model C & 2-C & $312.2-315.8$ \\
\hline Model D & 2-D & $312.1-315.7$ \\
\hline Model E & 2-E & $313-316.8$ \\
\hline \multicolumn{2}{|c|}{ Flat plate } & $339.9-340.3$ \\
\hline Model A & 3-A & $315.2-310.7$ \\
\hline Model B & 3-B & $311.3-314.8$ \\
\hline Model C & 3-C & $310.6-314.1$ \\
\hline Model D & 3-D & $310.6-314.2$ \\
\hline Model E & 3-E & $311.3-315$ \\
\hline
\end{tabular}

Through the paragraphs that have been presented, we reach conclusions as follows:-

In multi-jet impingement, for middle nozzles, the heat transfer peak was directly on the jet centerline. The cross-flow is still minor. As the cross flow developed, the peak position of the outer nozzles is observed to shift slightly downstream to rise cross flow moved the jets effect. The comparison of temperature distribution between the models have concave end and the others. The concave end of fin array at one side or two side of heat sink is the better state. Reveals that these results are in tune with our latter discussed results. Through this comparison it was confirmed that:-

- However model A have the smaller surface area but it has better dissipation the temperature than (model B) and (model E)

- All state fin-heat sink are safety to use and all are better than flat plate heat sink.

- Models (B, C, D and E) have the same numbers of (concave - convex) arcs and have the same surface area, although model $\mathrm{D}$ has the same of model $\mathrm{E}$ except it reflected, but the result showed that model $\mathrm{E}$ is the worst, and model $\mathrm{D}$ is the best.

- Model C is nearest to model D than the other models.

- Model B is nearest to model E than the other models.

- Having concave arc near the exit of the heat sink models (C-D) give better effect than having convex arcs near the exit (model E).

a validation case was recognized based on the research published in 2020 belongs to Basim Freegah, conducted to confirm results obtained from the simulation run were true and the assumptions and models used were valid. By using numerical results from Basim Freegah et. al. [12] work on numerical analysis by using Plate-fin of heat sinks (PFHS) without fillet profile using the parallel flow type. Across the z-axis, coolant flows into the heat sink. This state was taken to establish and prove the accurate of it result. (Table .6) view the geometry that taken in validation.

Table 6: The geometry that taken in validation

\begin{tabular}{|c|c|c|}
\hline No. of fins & Length of base & Thickness of base \\
\hline 10 & $40 \mathrm{~mm}$ & $5 \mathrm{~mm}$ \\
\hline thickness of fins & Width of base & Flow rate \\
\hline $1 \mathrm{~mm}$ & $39.7 \mathrm{~mm}$ & $0.0092 \mathrm{Kg} / \mathrm{s}$ \\
\hline High of fin & Space between two fins & \\
\hline $20 \mathrm{~mm}$ & $3.3 \mathrm{~mm}$ & \\
\hline
\end{tabular}

This model builds to numerically solve by using ANSYS Fluent (version 2019-R1) program with the same operation conditions. The result of validation of temperature of the (PFHS) at mass flow rate $\left(\mathrm{m}^{\circ}\right)=0.0092 \mathrm{~kg} / \mathrm{s}$ obey to parallel flow shows good correspondence between both models as show in (Fig 23). 


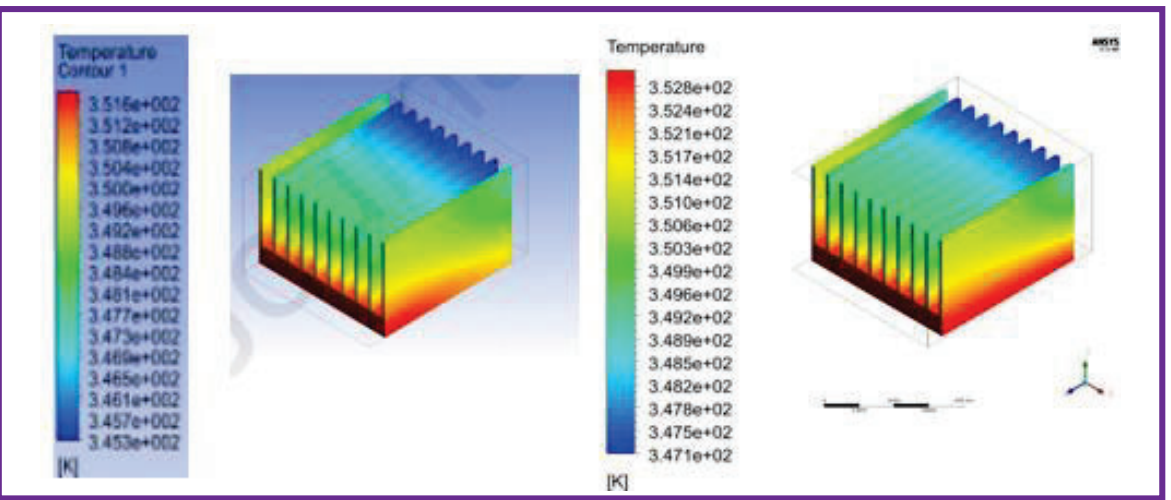

Fig. 23. Comparison of the validation results of Basim Freegah and present study

Comparison with [12] of diverse designs in impinging flow to examine the thermal performance of proposal designs when offer to impinging flow, the base temperature at $\mathrm{m}^{\circ}=0.0092 \mathrm{~kg} / \mathrm{s}$ have been presented for models (a-b-c-d-e-f). All that models were Compared to the base temperature counter for models (A-B-C-D-E) for present study at Re (7000-9000-11000) correspond mass flow rate $(0.005183 \mathrm{~kg} / \mathrm{s}-0.006597 \mathrm{Kg} / \mathrm{s}-0.008011 \mathrm{Kg} / \mathrm{s})$ respectively. Anywhere temperature display more active heat distribution.

At $\mathrm{q}^{\circ}(18750) \mathrm{W} / \mathrm{m}^{2}, \mathrm{~A}(40 \mathrm{~mm} \times 39.7 \mathrm{~mm})$, and $\mathrm{m}^{\circ}(0.0092) \mathrm{Kg} / \mathrm{s}$ were used in (Basim Freege) study.

The present study was presented in $\mathrm{q}^{\circ}(8333.33) \mathrm{W} / \mathrm{m}^{2}, \mathrm{~A}(60 \mathrm{~mm} \times 60 \mathrm{~mm})$, and $\mathrm{m}^{\circ}(0.005183 \mathrm{~kg} / \mathrm{s}-$ $0.006597 \mathrm{Kg} / \mathrm{s}-0.008011 \mathrm{Kg} / \mathrm{s}$ )

By changing the geometry and parameters of fins-heat sink with changing the mass flow rate, the improvement in the cooling of the dispersion base is achieved. All state of arcs-fin heat sink have better result by comparative with the research view. Show the (Fig 24).

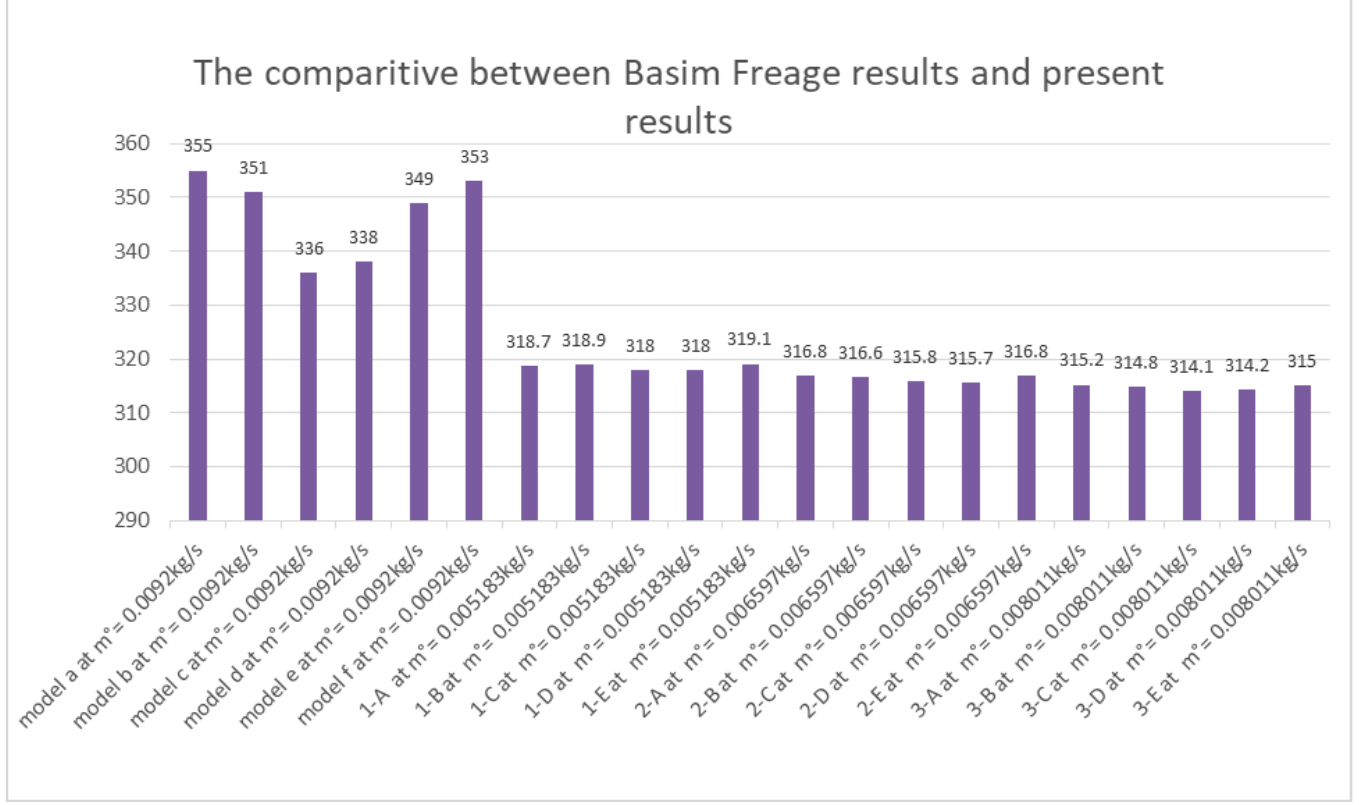

Fig 24.The comparative result between (Basim Freage) and Present research.

\section{Conclusions}

The focus of our study are investigation of heat transfer and fluid flow characteristics. New distribution of array jets impingement at different values of $(\mathrm{Re})$ at constant $\mathrm{Z} / \mathrm{d}$ with two types of heat sink (flat plate, arcs-fins) heat sink. The new model of array jets give:

- High saturated convection heat transfer coefficient in the core region and multi stagnation points.

- In multi jet impingement, the temperature distribution are more uniform.

The average temperature for the solid of the flat plate heat sink and five new models were presented too. The first model with configure from four concave arc at same radius, this model was change to consist from two concave arcs - two convex arcs that result the models (B-C-D-E). The optimized structure was obtained for minimum average temperature. By comparing the average temperature for the optimized (AFHS) with flat plate we find that the optimized (AFHS) possess lower average temperature.

The counter map is expected to be practically used as a guideline in the design of heat sink. 


\begin{tabular}{|ll|}
\hline \multicolumn{2}{l|}{ nomenclature } \\
1 & Length of jet, mm \\
$\mathrm{d}$ & Diameter, mm \\
$\mathrm{t}_{\mathrm{b}}$ & Thickness of plate, mm \\
$\mathrm{q}^{\circ}$ & heat flux, \\
$\mathrm{H}$ & height of fins , $\mathrm{mm}$ \\
$(\mathrm{n} \times \mathrm{n})$ & fin array \\
$(\mathrm{n}-1 \mathrm{x} \mathrm{n})$ & hole array in Nozzle plate \\
$\mathrm{R}$ & Radius of each arc of fin, mm \\
$\mathrm{S}_{\mathrm{L}}$ & longitudinal pitch of arc fin array, mm \\
$\mathrm{S}_{\mathrm{T}}$ & transverse pitch of arc fin array, mm \\
$\mathrm{Z} / \mathrm{d}$ & Ratio of jet to target plate spacing and nozzle \\
$\mathrm{Re}$ & Jet Reynolds based on jet velocity, \\
$\mathrm{A}$ & Base area of heat sink, mm ${ }^{2}$ \\
$\Delta \mathrm{p}$ & Pressure drop, KPa \\
$\mathrm{AFHS}$ & Arcs-fin heat sink \\
$\mathrm{K}$ & Thermal conductivity \\
\hline
\end{tabular}

\section{Acknowledgment}

The authors would like tothank Mustansiriyah University (http://www.uomustansiriyah.edu.iq), Baghdad- Iraq, for the given support in accomplishing the present work.

\section{References}

[1]A.shadlaghani,M.R.Tavakoli, MFarzaneh and M.R.Salimpour"Optimization of Triangular Fins With/Without Longitudinal Perforate for Thermal Performance Enhancement" Journal of Mechanical Science and Technology. Vol 30, no. 4, pp 1903-1910, 2015.

[2] Nagesh Kallappa Coagula"Computational and Experimental Study of Performance of Pin Fin Heat Sink under Jet Impingement". [PhD dissertation]University of Pune, 2012.

[3] Tzer-Ming Jeng, Sheng-Chung Tzeng and Hong-Ru Liao "Flow visualizations and heat transfer measurments for arotating pin -fin heat sink with a circular impinging jet". International Journal of Heat and Mass Transfer, vol 52, issue 7-8, pp 2119-2131, March. 2009.

[4] N. K. Chougule, G.V. Parishwad and C.M. Sewatkar, 2012, "Numerical Analysis of Pin Fin Heat Sink with a Single and Multi Air Jet Impingement Condition" International Journal of Engineering and Innovative Technology (IJEIT), vol 1,issue 3, pp. 44-50, March 2012.

[5]N. K. Chougule, G. V. Parishwad and A. R. Nadgire,"Numerical Investigation of Multijet Air Impingement on Pin Fin Heat Sink with Effusion Slots" Proceedings of the World Congress on Engineering and Computer Science, vol II,23-25 October, 2013, San Francisco, USA .

[6] Xueguan Song, Jie Zhang, Sanghoon Kang, Mingyao Ma, Bing Ji, Wenping Cao, Senior, and Volker Pickert "Surrogate-Based Analysis and Optimization for the Design of Heat Sinks With Jet Impingement" IEEE Transactions on Components, Packaging And Manufacturing Technology, vol. 4, no. 3 , pp. 429-437, March 2014.

[7] A. J. MORE, D. S. MANAKAR and N. P. BHONE "Experimental Study of High Heat Removal By Aluminum Pin Fin Heat Sink Using Multi-Jet Air Impingement" Trans Stellar, International Journal of Mechanical and Production Engineering Research and Development (IJMPERD), vol. 4, Issue 5, pp.1320,Oct.2014.

[8] Rıdvan YAKUT, Kenan YAKUT, Faruk YEŞİLDAL and Altuğ KARABEY "Experimental and Numerical Investigations of Impingement Air Jet for a Heat Sink ", IX International Conference on Computational Heat and Mass Transfer, Procedia Engineering, vol.157 pp. 3 - 12, 2016.

[9] Sk. Esub Basha, K. Lakshmi Prasad, G. Kartheek and K.V. Viswanath "Experimental Analysis of Jet Impingement on Aluminium Heat Sink" International Journal of Mechanical Engineering and Technology (IJMET), vol 9, Issue 6, pp. 1129-1140, June 2018.

[10] Zhipeng Duan, Xianghui Lv, Hao Ma, Liangbin Su and Mengqiao Zhang "Analysis of Flow Characteristics and Pressure Drop for an Impinging Plate Fin Heat Sink with Elliptic Bottom Profiles" Applied. Sciences, vol 10. 225, pp. 1-17, 2020.

[11]R.N.Mathul, R.M.Kasekar, N.P.Shevale, and S.R.Patil "Review of Heat Transfer Enhancement of Heat Sink Using Plate and Pin Fins" Ijarii-ISSN (o)-2395-4396, vol. 2, Issue 1, pp. 224-228, 2016.

[12] Basim Freegah, Ammar A. Hussain, Abeer H Falih, Hossein Towsyfyan " CFD analysis of heat transfer enhancement in plate-fin heat sinks with fillet profile: investigation of new designs" Thermal Science and Engineering Progress, vol 17, pp1-35, June 2020 